\title{
Characterization Studies of Reduced Graphene Oxide/Zinc Oxide Nanocomposites Synthesized by Hydrothermal Method
}

\author{
A. A. Ebnalwaled ${ }^{1}$, A. Abu El-Fadl ${ }^{2 *}$, Muhammad A. Tuhamy ${ }^{2}$ \\ 1. Department of Physics, Faculty of Science, South Valley University, Qena 83523, Egypt \\ 2. Department of Physics, Faculty of Science, Assiut University, Assiut 71516, Egypt \\ E-mail: abulfadla@yahoo.com
}

Received: 25 August 2019; Accepted: 15 September 2019; Available online: 5 November 2019

\begin{abstract}
Reduced graphene oxide/zinc oxide (RGO/ZnO) nanocomposites were synthesized by facile hydrothermal method; this method consists of exfoliation of graphite with modified Hummer's method and synthesis of (RGO/ZnO) nanocomposites using hydrothermal method. X-ray diffraction, TEM and FT-IR spectroscopy were used for structure morphological characterization. Optical properties of the samples were studied by measuring their optical absorbance. It can be concluded from XRD analysis that there are improvements of crystallinity associated with the increase of the crystallite size, as well as the increase in both of the (Zn-O) bond length and unit cell volume with the increase of $\mathrm{ZnO}$ ratio in $\mathrm{RGO} / \mathrm{ZnO}$ nanocomposites. The morphological studies confirmed that the scale of $\mathrm{ZnO}$ particles is large and the size distribution is not uniform in samples of $\mathrm{RGO} / \mathrm{ZnO}$ and that most particles have average size of about $9 \mathrm{~nm}$ while some particles even have larger size. The optical absorption spectra show that the excitonic peak of the as-prepared samples is red shifted from $268 \mathrm{~nm}$ to $376 \mathrm{~nm}$ for reduced grapheme oxide (RGO) with the increase of $\mathrm{ZnO}$ ratio, and the optical band gap changes from 2.39 for pure RGO to $3.34 \mathrm{eV}$ for pure $\mathrm{ZnO}$. The effect of $\mathrm{UV}$ irradiation on the optical absorption nanocomposites at different UV doses was carried out using UV lamp.
\end{abstract}

Keywords: Reduced graphene oxide; Hydrothermal; Hummer's method; RGO/ZnO nanocomposites; optical energy gap; UV irradiation.

\section{Introduction}

$\mathrm{ZnO}$ nanomaterials are attractive candidates for fabricating biosensors, super capacitors, solar cells, and another several electronic devices because of their diverse range of nanostructures, high electron mobility, chemical stability, and electrochemical activity, high isoelectric points which promote enzyme adsorption, bio compatibility, and piezoelectric properties [1]. Graphene which is a new important member in the family of carbon can be described as mono layer or a few layers of $2 \mathrm{D}$ planar sheet of $\mathrm{sp}^{2}$ hybridized carbon atoms arranged in a hexagonal lattice was first synthesized by modified Hummer's method [2]-[4]. It is a very good choice for electrode because of its characteristics, like excellent electrical conductivity, fast electron mobility, high surface area to volume ratio, and very good thermal and electrochemical properties [5]. Graphene has been widely studied for use in many electronics applications, due to its large theoretical surface area, good electronic conductivity, mechanical properties, and exceptional thermal stability, high electrical activity, good optical transmittance [6]. Graphene as a new member of the family of carbon can be used as an ideal choice for preparing nanocomposites like metal oxides, metal sulfides and metal nanoparticles for improved properties. The graphene based materials are widely used in several applications like, photo catalysis [7], energy storage, gas sensors [3]and biosensors [3], [8]-[12], light emitting diodes (LED) [13] Graphene and other carbon-based materials show a good conductivity when they coupled with metal oxides [14].

Reduced Graphene oxide has been synthesized by different methods such as chemical vapor deposition (CVD), micro mechanical exfoliation, epitaxial growth, thermal reduction and chemical methods (modified Hummer method) [2], [15]. Among those methods Hummer's method and it's modifies are the most used methods [16].

Among the many metal oxides, zinc oxide $(\mathrm{ZnO})$ is the most attractive as a promising material because of its low cost, rich availability, environmental friendly nature and electrochemical activity and direct wide band-gap about $3.37 \mathrm{eV}$ [1]. RGO/ZnO nanocomposites may exhibit unique properties due to the interactive effect between graphene and $\mathrm{ZnO}$ for improved electrical conductivity and electron transfer rate (electron mobility) [17]. The attracting properties of $\mathrm{RGO} / \mathrm{ZnO}$ nanocomposites have been widely studied like enhanced photo catalytic performance [18], energy storage capability, sensing property, optoelectronic property and ultra-fast nonlinear optical switching ability [19]. 
In the present investigation reduced graphene oxide synthesized by modified Hummer's method, Zinc oxide synthesized by hydrothermal method, and RGO/ZnO nanocomposites were synthesized by hydrothermal method and various characterization techniques have been employed to investigate the structure, morphology and optical absorption spectra for the prepared samples.

\section{Experimental}

\subsection{Materials}

Graphite powder (99\%) and hydrazine hydrates purchased from Fisher Scientific, (United Kingdom), zinc acetate dihydrate $\left(\left(\mathrm{CH}_{3} \mathrm{COO}\right)_{2} \mathrm{Zn}_{2} \cdot \mathrm{H}_{2} \mathrm{O}\right)$ (98\%) purchased from Oxford Laboratory Reagent, India, sodium hydroxide pellets $(\mathrm{NaOH})$ purchased from Fisher Scientific, United Kingdom, potassium permanganate $\left(\mathrm{KMnO}_{4}\right)$ (99\%), sulfuric acid (98\%), hydrochloric acid ( $\mathrm{HCl})(38 \%)$ and hydrogen peroxide $\left(\mathrm{H}_{2} \mathrm{O}_{2}\right)(30 \%)$ purchased from El-Nasr Pharmaceutical Chemical Egypt. All the commercial chemical reagents which used in this experiment were used without further precipitation and distilled water was used in all experiment.

$\mathrm{ZnO}$ nanoparticles were prepared according to equations (1), (2) and the residual sodium salt $\mathrm{CH}_{3} \mathrm{COONa}$ was removed by washing the sample with absolute ethanol and distilled water for several times [15], [16], [19].

$$
\begin{aligned}
& \mathrm{Zn}\left(\mathrm{CH}_{3} \mathrm{COO}\right)_{2} \cdot 2 \mathrm{H}_{2} \mathrm{O}+2 \mathrm{NaOH} \rightarrow \mathrm{Zn}(\mathrm{OH})_{2}+2 \mathrm{CH}_{3} \mathrm{COONa}+2 \mathrm{H}_{2} \mathrm{O} \\
& \mathrm{Zn}(\mathrm{OH})_{2}+2 \mathrm{H}_{2} \mathrm{O} \rightarrow \mathrm{Zn}(\mathrm{OH})_{4}^{-2}+2 \mathrm{H}^{+} \\
& \mathrm{Zn}(\mathrm{OH})_{4}^{-2} \rightarrow \mathrm{ZnO}+\mathrm{H}_{2} \mathrm{O}+2 \mathrm{OH}
\end{aligned}
$$

\subsection{Preparation of reduced graphene oxide (RGO)}

Reduced graphene oxide in nano form prepared via modified Hummer's method. Reduced graphene oxide (RGO) synthesis can be distinguished into two major steps, firstly oxidation of graphite flakes into exfoliated graphene oxide (GO) and reduction GO into RGO. Starting with graphite powder washed with hydrochloric acid (HCl) then washed with distilled water several times, then the powder dissolved in concentrated sulfuric acid. Soft potassium permanganate added wisely to the solution, the solution temperature must be less than $20^{\circ} \mathrm{C}$ by putting the mixture in ice bath. After stirring for 45 minutes the mixture diluted by adding wisely $100 \mathrm{~mL}$ of distilled water. The mixture heated up to $90^{\circ} \mathrm{C}$ then $40 \mathrm{~mL}$ of hydrogen peroxide was added, after stirring for 30 minutes the mixture let a night to precipitate and washed by $\mathrm{HCl}$ then washed several times by distilled water and then the powder was filtered and graphite oxide powder was obtained [3], [4], [16], [20]. Graphite oxide powder was dissolved in distilled water and the black suspension transferred into sonication $(50 \mathrm{~Hz})$ for $180 \mathrm{~min}$ at room temperature to exfoliate the stacked graphite oxide sheets into graphene oxide (GO), then the black suspension centrifuged for 30 min at $1000 \mathrm{rpm}$ to remove the aggregation from graphene oxide also to remove the unexfoliated graphite, then the powder was filtered and washed by distilled water and ethanol several times, and dried at $100^{\circ} \mathrm{C}$. The second step to obtain reduced graphene oxide is reducing the obtained graphene oxide by adding $0.5 \mathrm{~g}$ of the obtained GO to $1000 \mathrm{~mL}$ of distilled water and $5 \mathrm{~mL}$ of hydrazine hydrate then the mixture transferred into reflux system at $100^{\circ} \mathrm{C}$ for $24 \mathrm{~h}$. to reduce graphene oxide into reduced graphene oxide (removing oxygen containing groups). For 24 hours then suspension washed several times by distilled water then filtered and dried at $100^{\circ} \mathrm{C}$ to obtain RGO.

\subsection{Preparation of reduced graphene oxide (RGO) /zinc oxide (ZnO) nanocomposites}

Reduced graphene oxide (RGO) powder and zinc acetate in different ratios as shown in table 1 are dissolved in water and stirred for $15 \mathrm{~min}$, then $1 \mathrm{M}$ of $\mathrm{NaOH}$ dropped wisely to the mixture until achieve $\mathrm{pH}=10$ and the white mixture was transferred into Teflon autoclave hydrothermal system for $24 \mathrm{~h}$ at $100{ }^{\circ} \mathrm{C}$, then the product powder was filtered and washed by distilled water and ethanol, then dry at $100{ }^{\circ} \mathrm{C}$.

Table 1. Different mass ratios of reduced graphene oxide to zinc oxide precursors used to form $\mathrm{RGO} / \mathrm{ZnO}$ nanocomposites.

\begin{tabular}{llll}
\hline Name & Mass of RGO (g) & Mass of zinc acetate (g) & Weight ratio of RGO:Zn \\
\hline ZnO & 0 & 5 & $0: 1$ \\
$\mathrm{RGO}$ & 1 & 0 & $1: 0$ \\
$\mathrm{G} / \mathrm{Zn} 1$ & 1 & 1 & $1: 1$ \\
$\mathrm{G} / \mathrm{Zn} 2$ & 1 & 2 & $1: 2$ \\
$\mathrm{G} / \mathrm{Zn} 3$ & 1 & 3 & $1: 3$ \\
$\mathrm{G} / \mathrm{Zn} 4$ & 1 & 4 & $1: 4$ \\
$\mathrm{G} / \mathrm{Zn} 5$ & 1 & 5 & $1: 5$ \\
\hline
\end{tabular}




\subsection{Instrumentation and characterizations}

The phase and crystalline size of the prepared samples were characterized using an automated X-ray powder diffractometer (Philips diffractometer 1710 with $\mathrm{Cu}$ target and graphite monochromator with the incident wavelength of $0.15418 \mathrm{~nm}$ ). The morphological studies of samples were carried out using a transmission electron microscope (TEM) [JEOL JEM 1010] Japan performed at acceleration voltage of $200 \mathrm{KV}$ ].

Fourier transform infrared spectroscopy (FT-IR) analysis was carried out on a (Jasco Model-4000 Japan) 360 spectrometer to determine the specific functional groups present in the sample by $\mathrm{KBr}$ method.

UV-VIS spectrophotometer, UV2300, TECNOMOP was used to measure the absorbance, and transmittance of the prepared samples with wavelength scan from 190 to $1100 \mathrm{~nm}$.

The UV irradiation at different exposure time (t) with the same concentration of colloidal solution were studied using Cole-Parmer 6-watt UV Lamp with 365 nm Wavelength and White Light Tubes.

\section{Results and discussion}

\subsection{Structural studies}

The crystalline structures, crystal size and phase purity of RGO, ZnO powders, and $\mathrm{RGO} / \mathrm{ZnO}$ nanocomposites in different ratios were studied using XRD. The XRD patterns of the as synthesized pure $\mathrm{ZnO}$ and Pure RGO are shown in Fig. 1. (a) The XRD patterns of the synthesized (RGO/ZnO) nanocomposites materials are shown in Fig. 1. (b). XRD patterns were calculated in the range of $20^{\circ}$ to $80^{\circ}$ with step $0.06^{\circ}$. XRD main peaks are shown in Fig. 1. (a) indicate the presence of highly crystalline $\mathrm{ZnO}$ nanoparticles with a hexagonal structure (ICDD card no: 00001-1136) with calculated d-spacing of $2.7 \AA$ and $a=b=2.5 \AA$ and $c=3.99 \AA$. Zinc oxide main peaks are sharp and confirming high crystallinity of the samples with main peak at $2 \theta=36.52^{\circ}(101)$. These peaks correspond to (100), (002), (101), (102), (110), (103), (200), (112), and (201) crystalline planes related to the standard data of the ZnO. It is observed that peaks corresponding $\mathrm{ZnO}$ crystalline phase were detected in the XRD patterns of the samples with $2 \Theta$ values $\left(31.977^{\circ}, 34.64^{\circ}, 36.52^{\circ}, 47.77^{\circ}, 56.833^{\circ}, 63.096^{\circ}, 66.607^{\circ}, 68.181^{\circ}, 69.31^{\circ}, 72.804^{\circ}, 77.182^{\circ}\right.$, $81.52^{\circ}, 89.823^{\circ}$ ) with hexagonal structure. Although in Graphene Main peaks are existed at $2 \theta=26.324^{\circ}, 42.28^{\circ}$, $44.32^{\circ}, 54.411^{\circ}$, and $72.16^{\circ}$ with hexagonal structure (ICDD card no: 00-001-0640) corresponding to d-spacing of $2.799 \AA$, $a=b=3.506 \AA$ and $c=5.598 \AA$.

Fig. 1. (b) show that Zinc oxide main characterizing peaks appear with small intensity at RGO/Zn1 then the peaks intensity increase directly through different weight ratios from RGO/Zn1 to RGO/Zn5 although the intensity of graphene characterizing main peak are decreased. Fig. 2 shows the graphene main characterizing peak in different composite ratios was shifted to right with the increasing of zinc oxide content in the composite. The strong and sharp zinc oxide characterizing peaks in $\mathrm{RGO} / \mathrm{ZnO}$ nanocomposites tell us that the $\mathrm{ZnO}$ nanoparticles stacked to graphene nanosheets are still crystalline as in the pure sample.

(a)

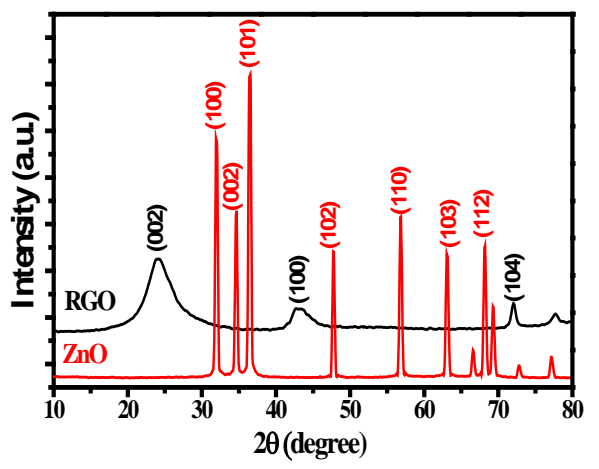

(b)

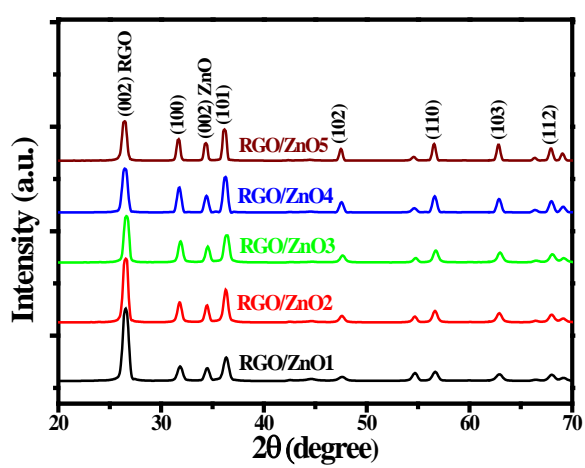

Fig. 1. (a) XRD patterns for pure reduced graphene oxide (RGO) and pure zinc oxide (ZnO), (b) XRD patterns for $\mathrm{RGO} / \mathrm{ZnO}$ nanocomposites.

The lattice constants a, and c of a hexagonal plane for ZnO, RGO and RGO/ZnO nanocomposites are calculated using the following equation:

$\frac{1}{\mathrm{~d}^{2}}=\frac{4}{3}\left(\frac{\mathrm{h}^{2}+\mathrm{hk}+\mathrm{k}^{2}}{\mathrm{a}^{2}}\right)+\frac{\mathrm{l}^{2}}{\mathrm{c}^{2}}$

For hexagonal crystal system the unit cell volume can be calculated using the formula: 
In the other hand the bond length $(\mathrm{L})$ can be evaluated by the equation:

$L=\sqrt{\frac{a^{2}}{3}+\left(\frac{1}{2}-z\right)^{2} c^{2}}$, where $z=\frac{a^{2}}{3}+\frac{1}{4}$

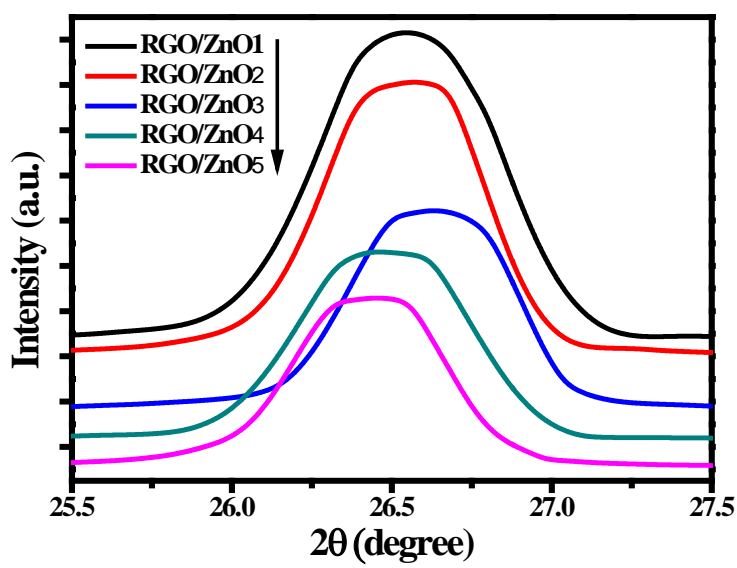

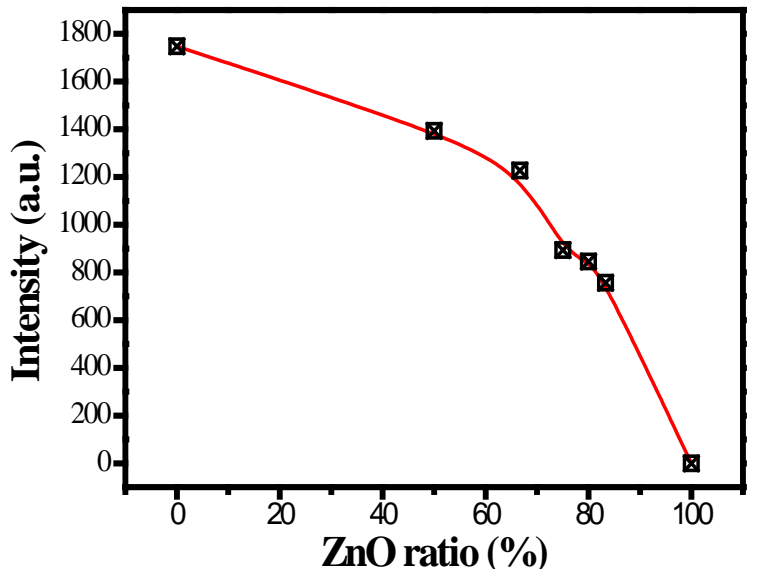

Fig. 2. The peak shift of (002) crystalline plane of RGO/ZnO nanocomposites.

The average particle sizes can be estimated from the maximum intensity peak corresponding to (002) plane by using Debye-Scherrer's formula according to the following equation [21]:

$$
\mathrm{D}_{\mathrm{hkl}}=\frac{0.94 \lambda}{\beta_{\mathrm{hkl}} \cos \theta}
$$

Where $\lambda$ is the wavelength of the incident X-ray beams ( $\lambda=1.5418 \AA), \theta$ is the diffraction angle, and $\beta_{\mathrm{hkl}}$ is the FWHM corrected for the instrumental broadening of the XRD peaks. It is found that the grain size of the samples is start with RGO about $8.8 \mathrm{~nm}$ in graphene and increases with increase of zinc oxide ratio in nanocomposites to reach about $22.5 \mathrm{~nm}$ in $\mathrm{RGO} / \mathrm{Zn} 5$ and reaches $24.8 \mathrm{~nm}$ for pure $\mathrm{ZnO}$ sample. These findings indicate that the $\mathrm{ZnO}$ decorated on the RGO nanosheets in $\mathrm{RGO} / \mathrm{ZnO}$ nanocomposites with a particle size ranges from 8.8 to $24.8 \mathrm{~nm}$ (according to the Debye-Scherer's formula). The increasing in grain size may be due to the increase in the both of $\mathrm{Zn}-\mathrm{O}$ bond length and unit cell volume with increase in $\mathrm{ZnO}$ mass ratio (Fig. 3).

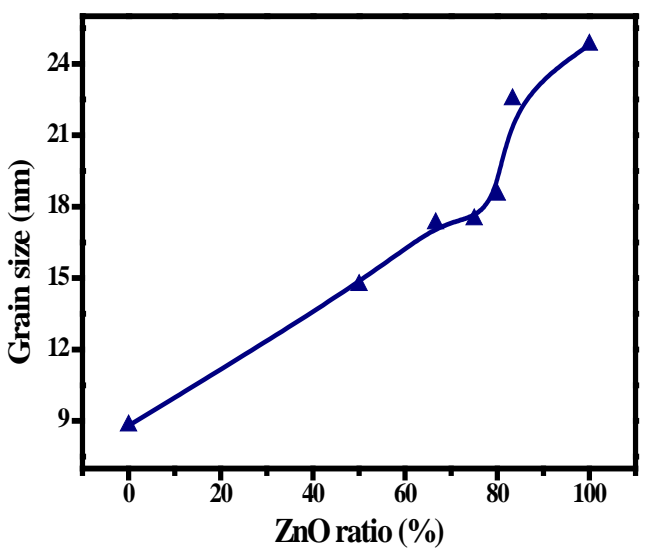

Fig. 3. The dependence of the grain size in $\mathrm{RGO} / \mathrm{ZnO}$ nanocomposites with $\mathrm{ZnO}$ ratio.

Crystallite size and lattice strain is determined using Williamson-Hall (W-H) equation [22]:

$$
\frac{\beta \cos \theta}{\lambda}=\frac{1}{D}+\frac{4 \varepsilon \sin \theta}{\lambda}
$$


where $\beta$ is the full width at half maximum (FWHM), $\Theta$ is the diffraction angle, $\lambda$ is $\mathrm{X}$-ray wavelength, $\mathrm{D}$ is the crystalline size and $\varepsilon$ is the lattice strain.

The dislocation density $(\delta)$ was calculated using the relation [23]:

$$
\delta=1 / \mathrm{D}^{2}
$$

According to Hook's law, for small dislocations in a lattice, a linear relation between the stress $\sigma$ and strain is given as $\sigma=\mathrm{Y} \varepsilon$, where Young's modulus $\mathrm{Y}$ (for hexagonal structure) can be represented by the following relation:

$$
\mathrm{Y}=\frac{\left(\mathrm{h}^{2}+\frac{(\mathrm{h}+2 \mathrm{k})^{2}}{3}+\left(\frac{\mathrm{al}}{\mathrm{c}}\right)^{2}\right)^{2}}{\mathrm{~s}_{11}\left(\mathrm{~h}^{2}+\frac{(\mathrm{h}+2 \mathrm{k})^{2}}{3}\right)+\mathrm{s}_{33}\left(\frac{\mathrm{al}}{\mathrm{c}}\right)^{4}+\left(2 \mathrm{~s}_{13}+\mathrm{s}_{44}\right)\left(\mathrm{h}^{2}+\frac{(\mathrm{h}+2 \mathrm{k})^{2}}{3}\right)\left(\frac{\mathrm{al}}{\mathrm{c}}\right)^{2}}
$$

where $\mathrm{s}_{11}, \mathrm{~s}_{13}, \mathrm{~s}_{33}, \mathrm{~s}_{44}$ are the lattice compliances of $\mathrm{ZnO}$ which equal to $7.858 \times 10^{-12},-2.206 \times 10^{-12}, 6.940 \times 10^{-12}$, and $23.57 \times 10^{-12} \mathrm{~m}^{2} \mathrm{~N}^{-1}$ respectively. The energy density u (the energy per unit volume of a lattice) can be calculated from Hook's law $\mathrm{u}=\left(\varepsilon^{2} \mathrm{Y}_{\mathrm{hkl}}\right) / 2$. Values of $\varepsilon, \mathrm{Y}, \sigma, \mathrm{u}$, and the above-mentioned parameters of all samples are listed in table 2.

Table 2. The diffraction angle (20) value, crystallite size (D), lattice parameters (a, c and c/a), unit cell volume $(\mathrm{V})$, internal local strain $(\varepsilon)$, dislocation density $(\delta)$, Young modulus $(Y)$, internal stress $(\sigma)$, and

\begin{tabular}{|c|c|c|c|c|c|c|c|c|c|c|c|}
\hline \multirow[b]{2}{*}{ Name } & \multirow{2}{*}{$\begin{array}{c}2 \theta \text { of the } \\
\text { main } \\
\text { peak }\end{array}$} & \multirow{2}{*}{$\begin{array}{l}D_{\text {hkl }} \\
(\mathbf{n m})\end{array}$} & \multicolumn{3}{|c|}{ Lattice parameter } & \multirow{2}{*}{$\begin{array}{c}\mathbf{V} \\
\left(\AA^{3}\right)\end{array}$} & \multirow{2}{*}{$\begin{array}{c}\varepsilon \times 10^{-4} \\
\text { (radians) }\end{array}$} & \multirow{2}{*}{$\begin{array}{c}\delta \times 10^{15} \\
\left(\mathbf{l} / \mathbf{m}^{2}\right)\end{array}$} & \multirow{2}{*}{$\begin{array}{c}Y \times 10^{11} \\
\text { (Pascal) }\end{array}$} & \multirow{2}{*}{$\begin{array}{c}\sigma \times 10^{8} \\
(\text { Pascal) }\end{array}$} & \multirow{2}{*}{$\begin{array}{l}u \times 10^{5} \\
\left(\mathrm{~J} / \mathrm{m}^{3}\right)\end{array}$} \\
\hline & & & a $(\AA)$ & c $(\AA)$ & $\mathbf{c} / \mathbf{a}$ & & & & & & \\
\hline $\mathrm{ZnO}$ & 36.52 & 24.8 & 3.621 & 5.78 & 1.596 & 65.6 & 14.6 & 1.62 & 2.47 & 3.6 & 5.26 \\
\hline RGO & 26.324 & 8.8 & 3.192 & 5.103 & 1.596 & 44.9 & 75.9 & 12.9 & 2.36 & 17.9 & 135.1 \\
\hline G/Zn1 & 26.551 & 17.7 & 3.384 & 5.402 & 1.596 & 53.5 & 24.8 & 4.6 & 1.76 & 4.36 & 10.8 \\
\hline $\mathrm{G} / \mathrm{Zn} 2$ & 26.541 & 17.3 & 3.465 & 5.432 & 1.596 & 57.5 & 20.9 & 3.31 & 1.83 & 2.89 & 8,38 \\
\hline G/Zn3 & 26.63 & 17.46 & 3.459 & 5.422 & 1.596 & 57.8 & 20.8 & 3.2 & 1.83 & 2.84 & 7.95 \\
\hline G/Zn4 & 26.48 & 18.5 & 3.469 & 5.538 & 1.596 & 57.7 & 20.1 & 2.9 & 1.84 & 2,68 & 5.68 \\
\hline G/Zn5 & 26.43 & 22.5 & 3.566 & 5.693 & 1.596 & 62.69 & 16.3 & 1.9 & 1.84 & 2.41 & 3.9 \\
\hline
\end{tabular}
energy density (u) for Reduced graphene oxide/zinc oxide (RGO/ZnO) nanocomposites (main peak).

The crystallite size $D_{\text {hkl }}$ corresponds to main peak at $2 \theta=26.324^{\circ}$ of the plane (002) in graphene and at $2 \theta=36.52^{\circ}$ of the plane (101) in $\mathrm{ZnO}$ (other values recorded in table 2) was estimated using the Debye-Scherrer's formula.

\subsection{Morphological Study}

The TEM results manifest the transparent nature of the reduced graphene oxide indicating graphite was exfoliated into thin planar sheets and deposition of $\mathrm{ZnO}$ nanoparticles on the surface of the RGO sheets, which agree with the XRD pattern. Fig. 4(a, b, c) show TEM images with different magnifications for the three samples $\mathrm{RGO}, \mathrm{ZnO}$, and a selected ratio of the $\mathrm{RGO} / \mathrm{ZnO}$ nanocomposite. It is clear to find that the scale of the $\mathrm{ZnO}$ particles is small (compared with RGO nanosheets) and the size distribution is not uniform in sample of RGO/ZnO and that most particles have average size of about $24 \mathrm{~nm}$ while some particles even have larger size and others has a smaller size. It is known that TEM uses both the transmitted and the scattered beams to create the image. As shown from Fig. 4 (a, b) the uniform size and shape distribution of $\mathrm{ZnO}$ obtained at low hydrothermal reaction time and temperature have semi-spherical shape. From the TEM the nano size of the obtained ZnO is confirmed with values obtained from XRD calculations.

\subsection{Optical absorption studies}

Optical absorption spectrum of RGO, ZnO, and $\mathrm{RGO} / \mathrm{ZnO}$ nanocomposites samples were measured by UV-Vis spectrophotometer in the range 200-900 nm as shown in Fig. 5. (a, b, c). The figure depicted that for RGO there are main absorption peak at $246 \mathrm{~nm}$ and another shoulder at $299 \mathrm{~nm}$ which refer respectively to $(\mathrm{C}-\mathrm{C})$ and $(\mathrm{C}=\mathrm{C})$ bonds between the carbon atoms of reduced graphene oxide. In zinc oxide the main peak exists at $276 \mathrm{~nm}$, but in $\mathrm{RGO} / \mathrm{ZnO}$ nanocomposites in different ratios from $\mathrm{RGO} / \mathrm{ZnO} 1$ to $\mathrm{RGO} / \mathrm{ZnO} 5$ the exciton peak moved from 364 
$\mathrm{nm}$ to $374 \mathrm{~nm}$ which mean that zinc oxide nanoparticles are stacked well on RGO nanosheets and the displacement in the peak is due to the difference in $\mathrm{ZnO}$ ratio which agree with the images obtained by TEM.

The corresponding excitonic energy $\left(\mathrm{E}_{\mathrm{ex}}\right)$ can be calculated from the following formula:

$$
\mathrm{E}_{\mathrm{ex}}=\mathrm{hC} / \lambda_{\max }
$$

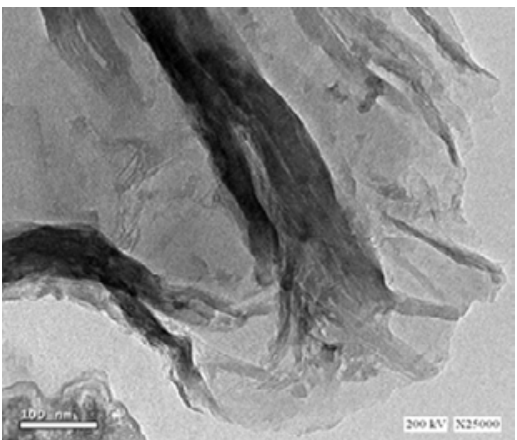

(a)

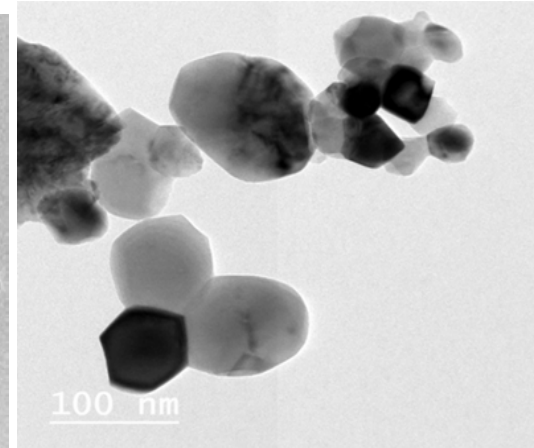

(b)

Fig. 4. TEM images of (a) reduced grapheme oxide (RGO), (b) pure $\mathrm{ZnO}$, and (c) for the RGO/ZnO nanocomposite.

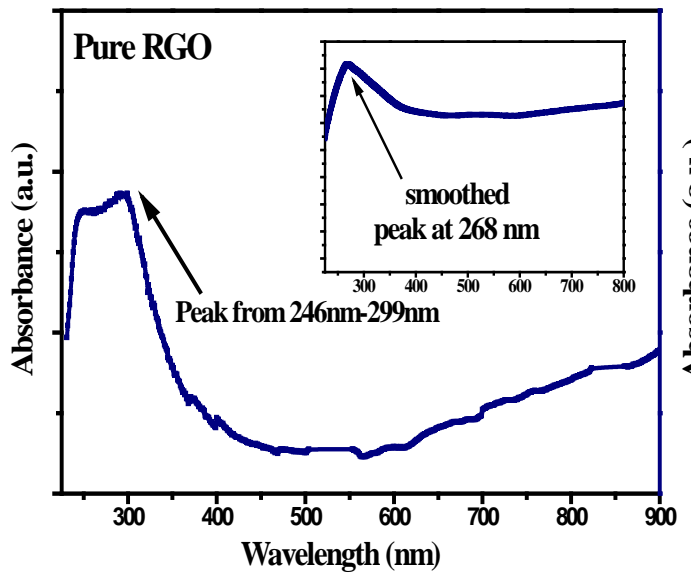

(a)

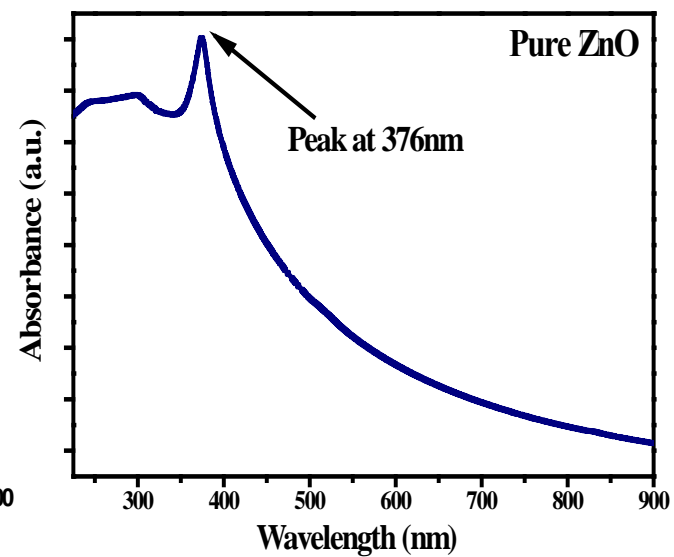

(b)

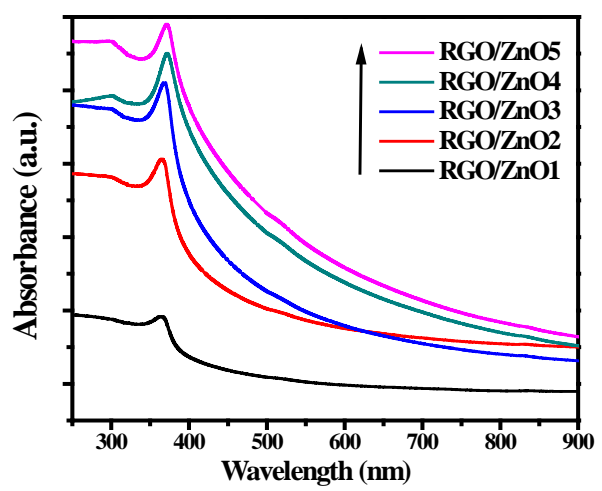

(c)

Fig. 5 (a) Absorption versus wavelength spectrum for RGO. The inset shown the smoothed peak at $268 \mathrm{~nm}$, (b) absorption versus wavelength spectrum for pure $\mathrm{ZnO}$, and (c) absorption versus the incident wavelength spectra for RGO/ZnO nanocomposites.

Where $\mathrm{h}$ is Planck's constant, $\mathrm{C}$ is the velocity of light, and $\lambda_{\max }$ is the exciton peak wavelength. It is shown that increasing $\mathrm{ZnO}$ ratio leads to a red shift in both exciton peaks. Usually Tauc's plot is the most verified method for obtaining the optical energy gap.The optical absorption spectra were analyzed according to Tauc`s relation in the form: 


$$
\alpha h v=B\left(\alpha h v-E_{g}\right)^{r}
$$

Where $\alpha$ is the absorption coefficient, $h v$ is the photon energy, $\mathrm{E}_{\mathrm{g}}$ is the optical band gap and B is the steepness or ordering parameter.

The Tauc's relation for direct band gap [24]:

$$
(\mathrm{Ahv})^{2}=\mathrm{B}\left(\mathrm{h} v-\mathrm{Eg}_{\mathrm{g}}\right)^{\mathrm{r}}
$$

Where $B$ is the edge width parameter, $E_{\mathrm{g}}$ is the optical energy gap of the material, which refer to the direct band gap of optical transitions. Fig. 6 describes the change in Exciton peak with $\mathrm{ZnO}$ mass ratio, and obviously show that $\mathrm{E}_{\mathrm{g}}$ values are increasing with the increasing $\mathrm{ZnO}$ ratio. That can be attributed to the higher $\mathrm{E}_{\mathrm{g}}$ value of $\mathrm{ZnO}$ when compared with that of RGO as shown in table 3.

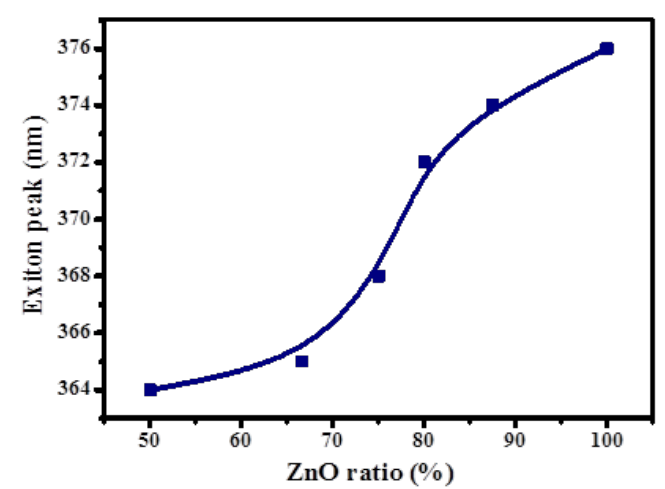

Fig. 6 The dependence of the optical energy gap and the corresponding exciton peak energy on $\mathrm{ZnO}$ ratio for $\mathrm{RGO} / \mathrm{ZnO}$ nanocomposites.

The noticeable increase in $\mathrm{E}_{\mathrm{g}}$ and $\mathrm{E}_{\mathrm{ex}}$ may be described to the increase in the crystallite size due to the improvement in crystallinity by $\mathrm{ZnO}$ incorporation in graphene matrix [25]-[28].

The absorption coefficients near the fundamental absorption edge are exponentially dependent on the photon energy, and obey Urbach’s empirical relation [29]:

$$
\begin{aligned}
& \alpha=\alpha_{0} \exp \left(\frac{h v}{E_{e}}\right) \\
& \operatorname{Ln} \alpha=\alpha_{0}+\left(\frac{h v}{E_{e}}\right)
\end{aligned}
$$

Where $\alpha_{0}$ is a constant and $E_{e}$ is the Urbach energy which is interpreted as the width of band tail of localized states in the band gap and in general represents the degree of disorder in an amorphous semiconductor. The absorption in this region is due to transitions between extended states in one band and localized states in the exponential tail of the other band.

The photon energy dependence of the absorption coefficient can be described by Urbach's relation given by Eqs. $(13,14)$. Fig. 7(a) shows a plot of $\ln (\alpha)$ versus $h v$ of pure RGO and pure ZnO. Fig. 7(b) shows a plot of $\ln (\alpha)$ versus $\mathrm{h} v$ of $\mathrm{RGO} / \mathrm{ZnO}$ nanocomposites. That should give a linear portion with a slope equal to the inverse of $\mathrm{E}_{\mathrm{e}}$ and the obtained $\mathrm{E}_{\mathrm{e}}$ values are given in Table 3. The $\mathrm{E}_{\mathrm{e}}$ values of the $\mathrm{RGO} / \mathrm{ZnO}$ are increased with increasing $\mathrm{ZnO}$ content. One noted that the values of $\mathrm{E}_{\mathrm{e}}$ are changed inversely with those of $\mathrm{E}_{\mathrm{g}}$ and this may be due to the increase of the disorder of RGO matrix by $\mathrm{ZnO}$ doping. This increase leads to distribution of states from band to tail and thus allows for many possible bands to exhibit tail to tail transitions.

Figure 8(a) shows the energy gap determination of pure RGO, Fig. 8(b) shows energy gap determination of pure $\mathrm{ZnO}$ and Fig. 8(c) shows the effect of $\mathrm{ZnO}$ ratio on energy gap value. Energy gap of $\mathrm{ZnO}$ is $3.34 \mathrm{eV}$ and 2.39 $\mathrm{eV}$ for reduced graphene oxide, and it's clear that energy gap is gradually increased with the increasing of $\mathrm{ZnO}$ content in composites may be energy gap in RGO is lower than the energy gap of $\mathrm{ZnO}$ or the increasing in grain size of nanocomposite with increasing in $\mathrm{ZnO}$ mass ratio.

The effect of UV irradiation on the absorption spectra and other optical properties was studied by putting diluted solution sample under UV light irradiation and measure the absorbance every half hour as shown in Figs. 9 \& 10 for RGO and $\mathrm{ZnO}$, respectively. Increasing UV irradiation dose results in enhancement in the absorption accompanied by a blue shift in $E_{g}$ values due to induced UV effect. 
(a)

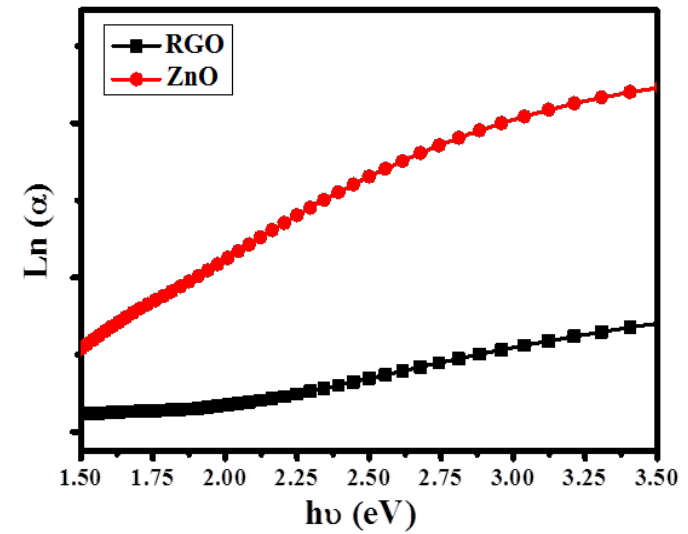

(b)

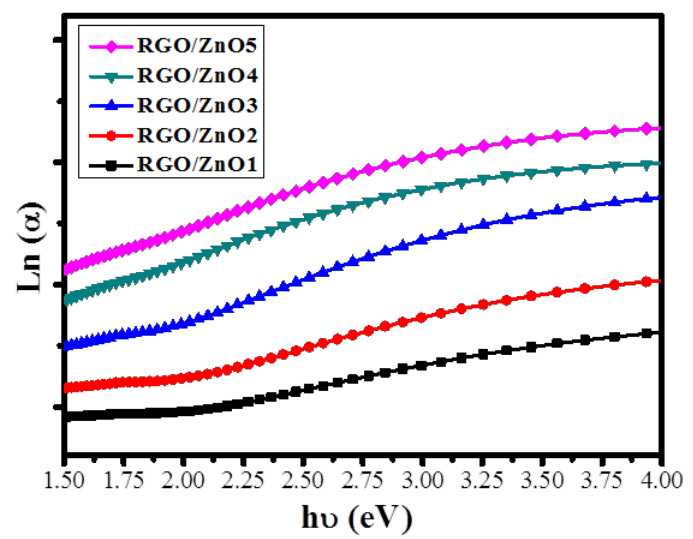

Fig. 7 (a) Plot of $\operatorname{Ln}(\alpha)$ versus hv of pure RGO and pure $\mathrm{ZnO}$, (b) $\ln \alpha$ versus hv for RGO/ZnO nanocomposites.

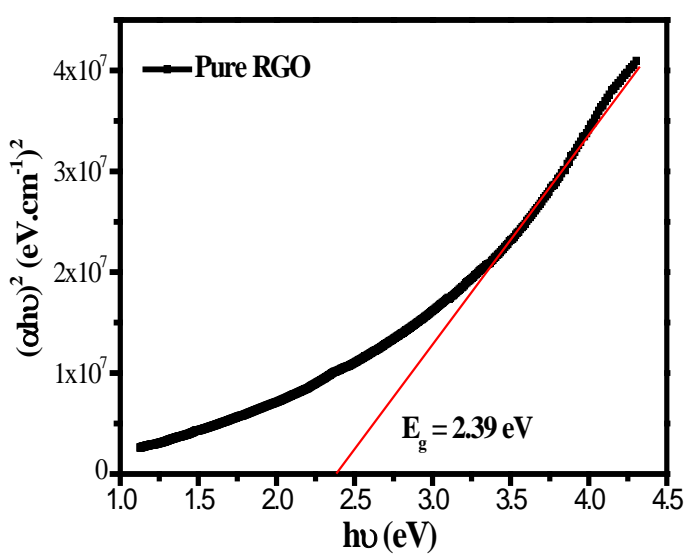

(a)

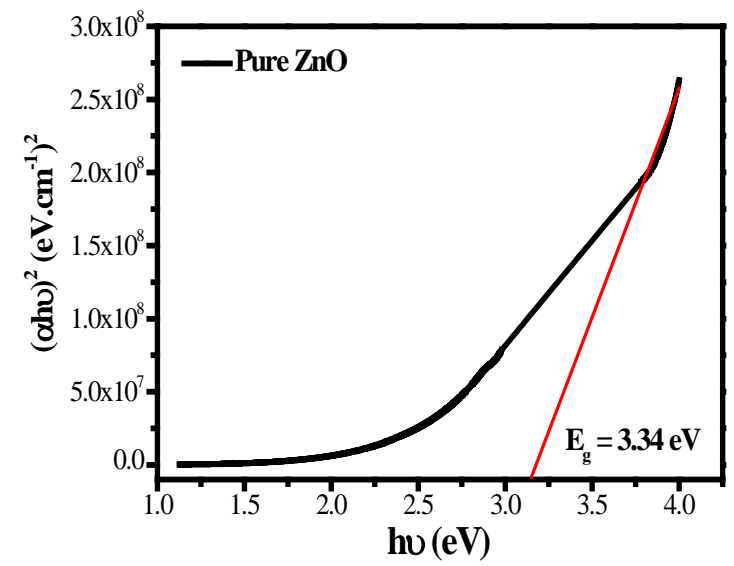

(b)

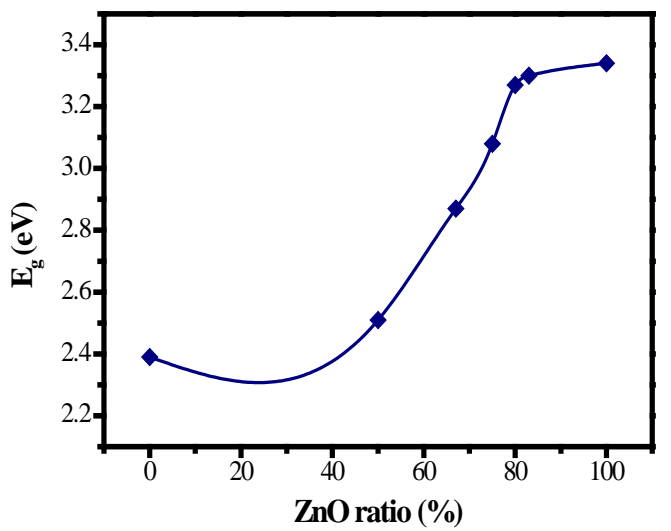

(c)

Fig. 8 (a) Energy gap determination of pure RGO, (b) Energy gap determination of pure ZnO, and (c) The dependence of energy gap on $\mathrm{ZnO}$ ratio.

Table 3. Exciton peak and energy gap ( $\mathrm{E}_{\mathrm{g}}$ ) for pure $\mathrm{ZnO}$, pure RGO and RGO/ZnO nanocomposites

\begin{tabular}{lll}
\hline Sample & Exciton peak $(\mathbf{n m})$ & Energy gap $(\mathbf{E g})(\mathbf{e V})$ \\
\hline ZnO & 376 & 3.34 \\
$\mathrm{RGO}$ & 268 & 2.39 \\
$\mathrm{RGO} / \mathrm{ZnO} 1$ & 361 & 2.51 \\
$\mathrm{RGO} / \mathrm{ZnO} 2$ & 365 & 2.87 \\
$\mathrm{RGO} / \mathrm{ZnO3}$ & 368 & 3.08 \\
$\mathrm{RGO} / \mathrm{ZnO} 4$ & 371 & 3.27 \\
$\mathrm{RGO} /$ ZnO5 & 372 & 3.3 \\
\hline
\end{tabular}


(a)

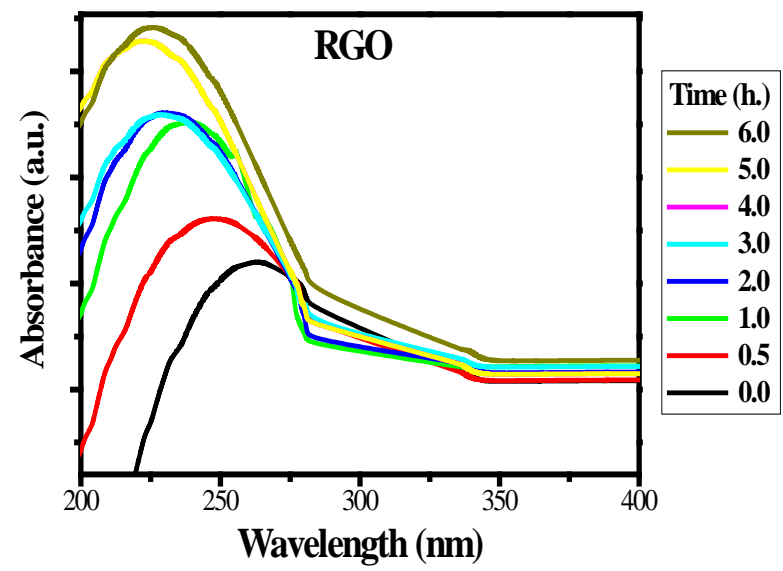

(b)

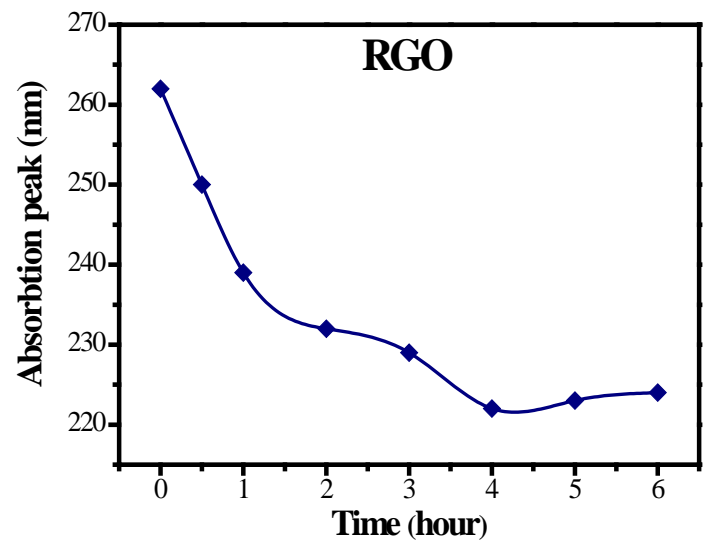

Fig. 9 (a) Effect of UV irradiation dose on the optical absorbance spectra of pure RGO, (b) Effect of UV irradiation dose on the optical absorbance peak of pure RGO.

(a)

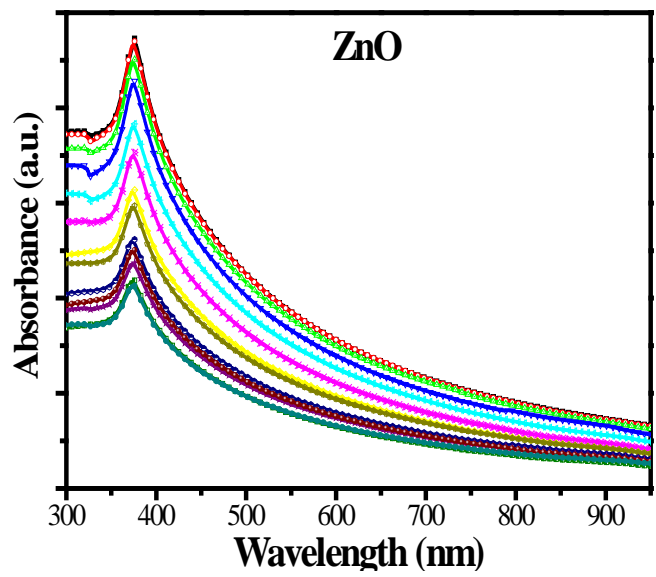

(b)

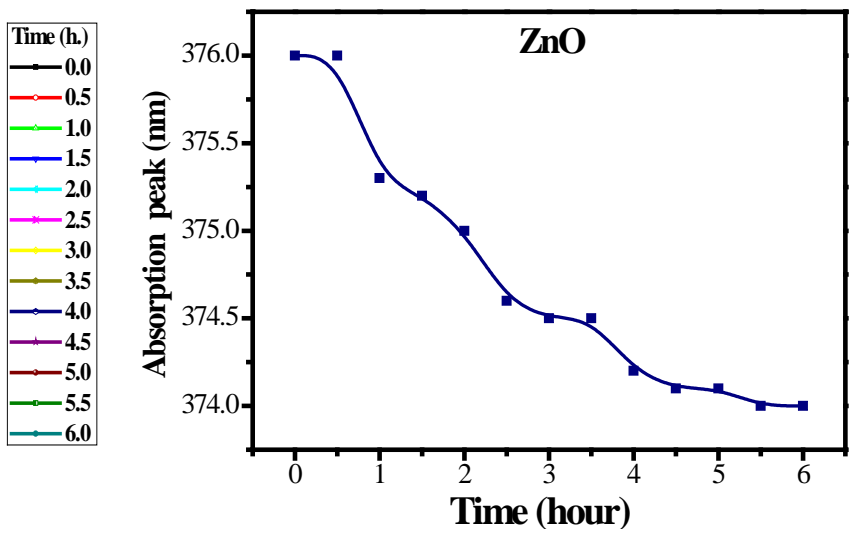

Fig. 10 (a) Effect of UV irradiation dose on the optical absorbance spectra of pure $\mathrm{ZnO}$, (b) Effect of UV irradiation dose on the optical absorbance peak of pure $\mathrm{ZnO}$.

\subsection{FT-IR Spectroscopy}

Fourier transforms infrared spectroscopy (FT-IR) is obtained as transmission spectra of $\mathrm{KBr}$ sample pellets in order to characterize the bond structure of $\mathrm{RGO}, \mathrm{ZnO}$, and $\mathrm{RGO} / \mathrm{ZnO}$ nanocomposites. Figure 11 shows (FT-IR) of $\mathrm{RGO}, \mathrm{ZnO}$, and $\mathrm{RGO} / \mathrm{ZnO}$ nanocomposites in the range of 4000 to $400 \mathrm{~cm}^{-1}$.

The absorption peak of reduced graphene oxide at the high frequencies centered at $3457 \mathrm{~cm}^{-1}$ refers to a large amount of hydroxyl group $(\mathrm{O}-\mathrm{H})$ which refer to the moisture in sample this may be from $\mathrm{KBr}$ or the sample contain some water remain after drying and also for the peak at $2341 \mathrm{~cm}^{-1}$. A wide spectral peak from $2000 \mathrm{~cm}^{-1}$ to 3500 $\mathrm{cm}^{-1}$ corresponding to the absorption of water molecules and that indicate the high of moisture of RGO. The transmittance peak at $1122 \mathrm{~cm}^{-1}$ represents the (C-O) bonds and (C-OH) on the surface of RGO nanosheets. On the other side, zinc oxide the absorption peak at high frequencies area also refer to the moisture of water molecule such as the peak at $3435 \mathrm{~cm}^{-1}$ and the peak at $562 \mathrm{~cm}^{-1}$ represent the (Zn-O) bonds as shown in table 4. Figure 11 shows that with increasing in $\mathrm{ZnO}$ mass ratio in samples ( $\mathrm{Zn}-\mathrm{O}$ ) bond peak is stretched and shifted to left.

\section{Conclusions}

In summery reduced grapheme oxide (RGO) were synthesized via modified Hummer's method at low temperature process and $\mathrm{RGO} / \mathrm{ZnO}$ nanocomposites were synthesized via facile low temperature hydrothermal method. It obviously from TEM images that ZnO nanoparticles are homogeneously decorated on the surface of RGO sheets and stack on RGO sheets. The values of the optical energy gap $\mathrm{E}_{\mathrm{g}}$ increase with increasing $\mathrm{ZnO}$ ratio in $\mathrm{RGO} / \mathrm{ZnO}$ nanocomposites, while the Urbach tail energy $\mathrm{E}_{\mathrm{e}}$ takes the opposite trend. The UV irradiation dose increment introduce an enhancement in the absorption spectral behavior accompanied by a blue shift in the optical energy gap values. FT-IR spectra ensure the formation of nanocomposites. This facile synthesis method can be 
easily used to the synthesis of other RGO-based hybrid nanocomposite materials for many purposes such as electrochemical based sensors or photodegradation.

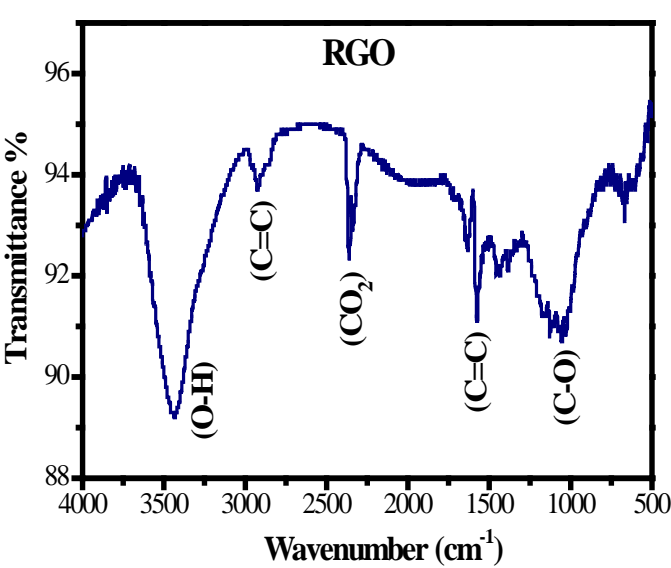

(a)

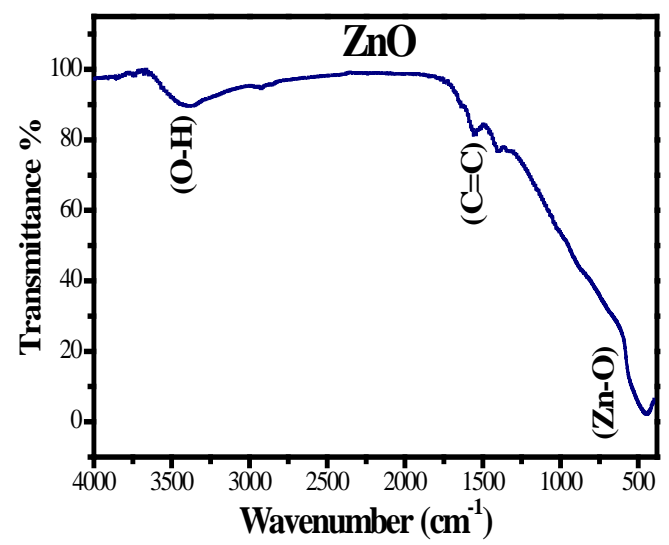

(b)

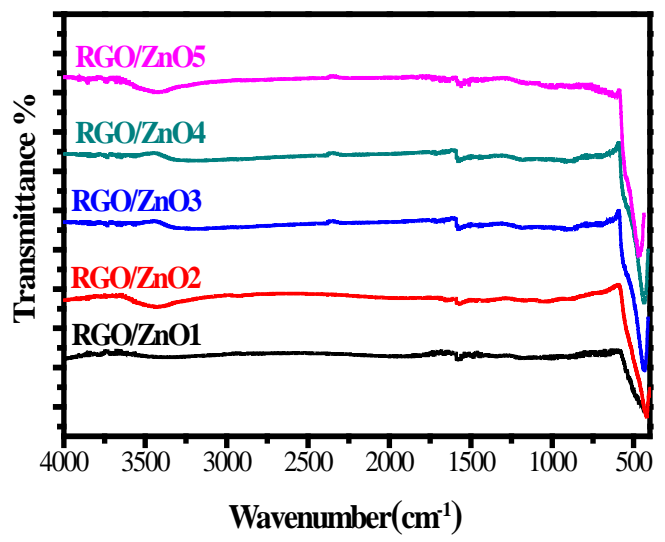

(c)

Fig. 11 FT-IR Spectroscopy of (a) pure RGO, (b) Pure ZnO, and (c) RGO/ZnO nanocomposites.

Table 4. FT-IR peaks and their characteristic bonds for $\mathrm{ZnO}$.

\begin{tabular}{llllllll}
\hline FT-IR peak $\left(\mathbf{c m}^{-1}\right)$ & 3435 & 2993 & 2861 & 2359 & 1635 & 1401 & 1122 \\
\hline Bond & $\mathrm{O}-\mathrm{H}$ & $\mathrm{C}-\mathrm{H}$ & $\mathrm{C}-\mathrm{H}$ & $\mathrm{CO}_{2}$ & $\mathrm{C}=\mathrm{C}$ & $\mathrm{C}=\mathrm{O}$ & $\mathrm{C}-\mathrm{O}$ \\
\hline
\end{tabular}

\section{References}

[1] Zhang Y, Kang Z, Yan X, Liao Q. ZnO nanostructures in enzyme biosensors. Science China Materials. 2015;58(1):60-76.

[2] Hummers Jr WS, Offeman RE. Preparation of graphitic oxide. Journal of the American Chemical Society. 1958;80(6):1339.

[3] Anand K, Singh O, Singh MP, Kaur J, Singh RC. Hydrogen sensor based on graphene/ZnO nanocomposite. Sensors and Actuators B: Chemical. 2014;195:409-415.

[4] Subramani K, Sathish M. Facile synthesis of $\mathrm{ZnO}$ nanoflowers/reduced graphene oxide nanocomposite using zinc hexacyanoferrate for supercapacitor applications. Materials Letters. 2019;236:424-427.

[5] Pumera M. Graphene in biosensing. Materials today. 2011;14(7-8):308-315.

[6] Park JW, Lee C, Jang J. High-performance field-effect transistor-type glucose biosensor based on nanohybrids of carboxylated polypyrrole nanotube wrapped graphene sheet transducer. Sensors and Actuators B: Chemical. 2015;208:532-537.

[7] Xiang Q, Yu J, Jaroniec M. Graphene-based semiconductor photocatalysts. Chemical Society Reviews. 2012;41(2):782-796.

[8] Bolotin KI, Sikes KJ, Jiang Z, Klima M, Fudenberg G, Hone J, Kim P, Stormer HL. Ultrahigh electron mobility in suspended graphene. Solid State Communications. 2008;146(9-10):351-355.

[9] Ning G, Fan Z, Wang G, Gao J, Qian W, Wei F. Gram-scale synthesis of nanomesh graphene with high 
surface area and its application in supercapacitor electrodes. Chemical Communications. 2011;47(21):59765798.

[10] Stankovich S, Dikin DA, Piner RD, Kohlhaas KA, Kleinhammes A, Jia Y, Wu Y, Nguyen ST, Ruoff RS. Synthesis of graphene-based nanosheets via chemical reduction of exfoliated graphite oxide. Carbon. 2007;45(7):1558-1565.

[11] Lin YM, Avouris P. Strong suppression of electrical noise in bilayer graphene nanodevices. Nano letters. 2008;8(8):2119-2125.

[12] Azarang M, Shuhaimi A, Yousefi R, Golsheikh AM, Sookhakian M. Synthesis and characterization of ZnO NPs/reduced graphene oxide nanocomposite prepared in gelatin medium as highly efficient photodegradation of MB. Ceramics International. 2014;40(7):10217-10221.

[13] Song SH, Jang MH, Chung J, Jin SH, Kim BH, Hur SH, Yoo S, Cho YH, Jeon S. Highly efficient light emitting diode of graphene quantum dots fabricated from graphite intercalation compounds. Advanced Optical Materials. 2014;2(11):1016-1023.

[14] Ezeigwe ER, Tan MT, Khiew PS, Siong CW. One-step green synthesis of graphene/ZnO nanocomposites for electrochemical capacitors. Ceramics International. 2015;41(1):715-724.

[15] Low SS, Tan MT, Loh HS, Khiew PS, Chiu WS. Facile hydrothermal growth graphene/ZnO nanocomposite for development of enhanced biosensor. Analytica Chimica Acta. 2016;903:131-141.

[16] Chia JS, Tan MT, Khiew PS, Chin JK, Lee H, Bien DC, Siong CW. A novel one step synthesis of graphene via sonochemical-assisted solvent exfoliation approach for electrochemical sensing application. Chemical Engineering Journal. 2014;249:270-278.

[17] Li Y, Wang D, Li W, He Y. Photoelectric conversion properties of electrochemically codeposited graphene oxide-ZnO nanocomposite films. Journal of Alloys and Compounds. 2015;648:942-950.

[18] Haghshenas SS, Nemati A, Simchi R, Kim CU. Photocatalytic and photoluminescence properties of ZnO/graphene quasi core-shell nanoparticles. Ceramics International. 2019;45(7):8945-8961.

[19] Ding J, Zhu S, Zhu T, Sun W, Li Q, Wei G, Su Z. Hydrothermal synthesis of zinc oxide-reduced graphene oxide nanocomposites for an electrochemical hydrazine sensor. RSC Advances. 2015;5(29):22935-22942.

[20] Conde MN, Dakhsi K, Zouihri H, Abdelouahdi K, Laanab L, Benaissa M, Jaber B. Preparation of ZnO nanoparticles without any annealing and ripening treatment. Journal of Materials Science and Engineering: A. 2011;1(7A):985.

[21] Scherrer P. Göttinger Nachrichten Math. Phys. 1918;2:98-100.

[22] Williamson GK, Hall WH. X-ray line broadening from filed aluminium and wolfram. Acta Metallurgica. 1953;1(1):22-31.

[23] Kumar S, Sharma P, Sharma V. CdS nanofilms: synthesis and the role of annealing on structural and optical properties. Journal of Applied Physics. 2012;111(4):043519.

[24] Tauc J, Menth A. States in the gap. Journal of Non-Crystalline Solids. 1972;8:569-585.

[25] Kamarulzaman N, Kasim MF, Rusdi R. Band gap narrowing and widening of ZnO nanostructures and doped materials. Nanoscale Research Letters. 2015;10(1):346.

[26] Sarma H, Chakrabortty D, Sarma KC. Structural and optical properties of Zno nano particles. IOSR Journal of Applied Physics. 2014;6(4):08-12.

[27] Joseph SL, John AO, Mugwang'a FK, Katana GG. Tuning the band gap energy of reduced graphene oxide using biopolymer chitosan for high power and frequency device applications. American Journal of Polymer Science \& Engineering. 2019;7(1):8-19.

[28] Prabhu S, Pudukudy M, Sohila S, Harish S, Navaneethan M, Navaneethan D, Ramesh R, Hayakawa Y. Synthesis, structural and optical properties of $\mathrm{ZnO}$ spindle/reduced graphene oxide composites with enhanced photocatalytic activity under visible light irradiation. Optical Materials. 2018;79:186-195.

[29] Kurik MV. Urbach rule. Physica Status Solidi (A). 1971;8(1):9-45.

(C) 2019 by the author(s). This work is licensed under a Creative Commons Attribution 4.0 International License (http://creativecommons.org/licenses/by/4.0/). Authors retain copyright of their work, with first publication rights granted to Tech Reviews Ltd. 